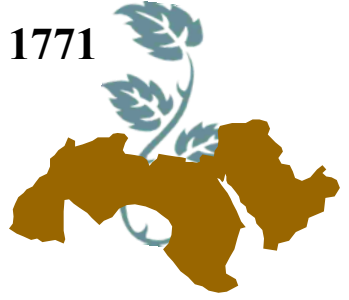

\author{
مجلة اتحاد الجامعات العربية

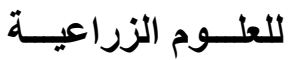 \\ جامعة عين شمس ، التقاهرة
}

مجلد(26)، عدد (2C)، عدد خاص ، الفرة ، 1787-1771، 2018

تكاليف صناعة ضرب الأرز في مصر

[130]

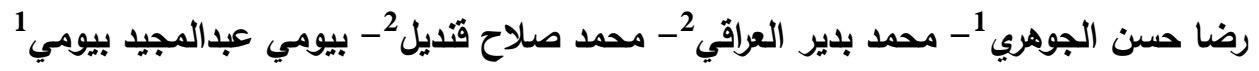

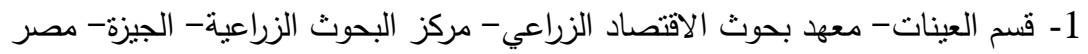

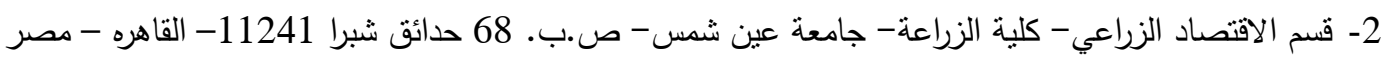

ويتم اقتراح أنسب الحلول لتحسين كفاءة هذه الصناعة

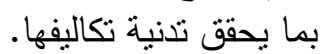

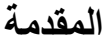

من المعروف أن الأرز الثعبر تتم صناعته داخل وحدات إنشائية (كبيرة وصغيرة) تشمى مضارب الأنير الأرز

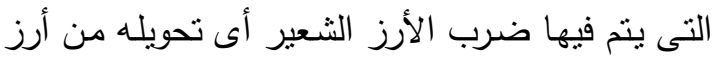

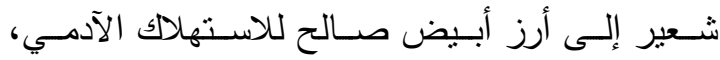

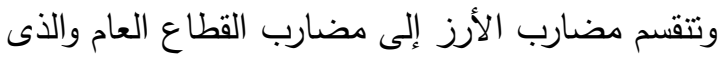

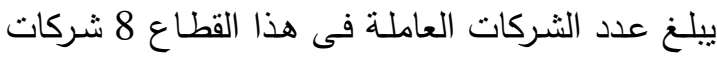

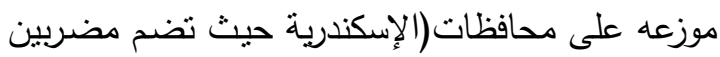
(رشيد -الإسكندرية) - البحيرة - كفر الثيخ - الإكلية - الغربية

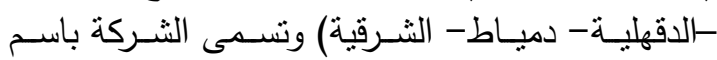

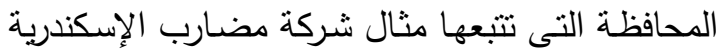

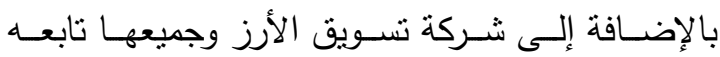

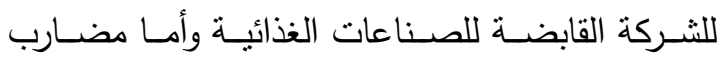

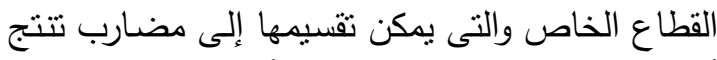

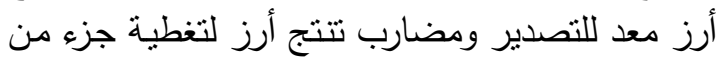

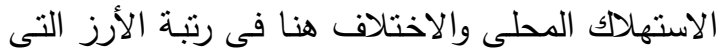

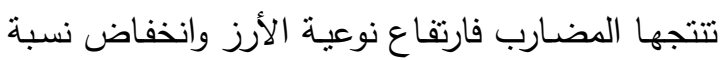

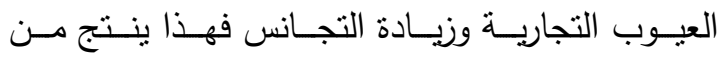

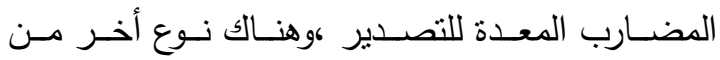

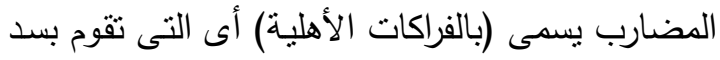
احتباجات اهالى القرية من الأرز الأبيض وهى الألى بدائية

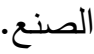

الكلمات الدالة: دوال التكاليف ، ضرب الارز ، تكاليف

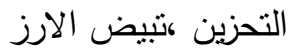

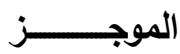

يستهدف هذا البحث بشكل عام دراسة تكاليف

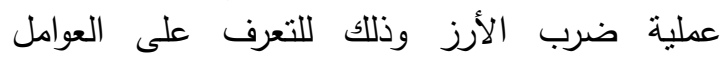

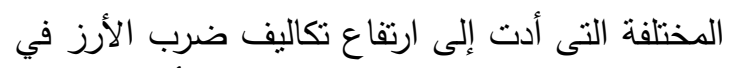

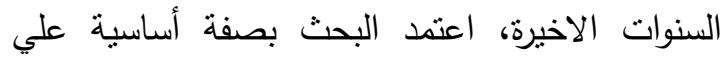

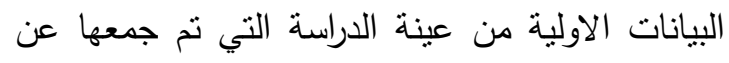

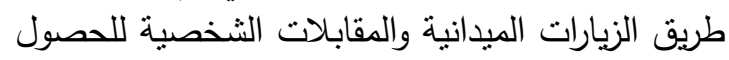

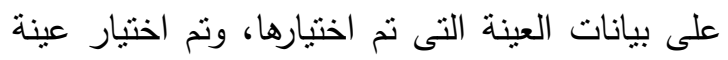
عمدية على مستوى المحافظات ثم على مستوى المراكز ثم على مستوى القرى ويبلغ عدد المضارب في علئ عينة الداسة 25 مضرب موزعة بالمناطق الاتية ثلاثة

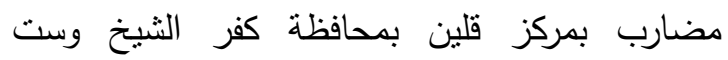
مضارب بالسالمية بمركز دسوق بمحافظة كفر الثيخ وثماني مضارب بمركز فوة بكفر الثيخ.

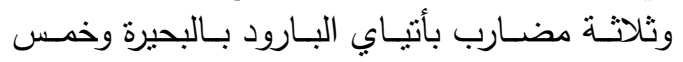

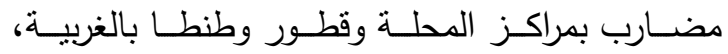

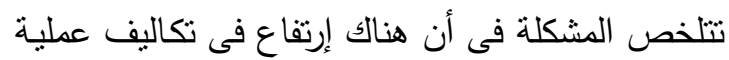

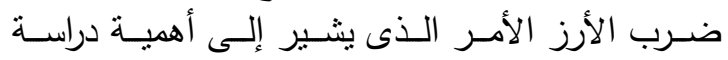

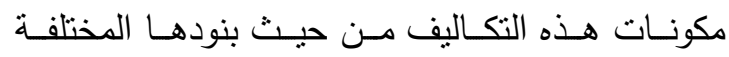
والعوامل المؤثرة عليها وأهم المشكلات التى تواجه هذه التها الصناعة وكيفية التغلب عليها وبالتالى إمكانية الوصول

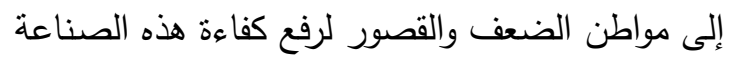

(سلم البحث فى 26 مارس 2018)

(المراجعة على البحث فى 16 مايو 2018 2018)

(الموافقة على البحث فى 10 يونيو 16 ينايو 2018) 
مصادر البيانات

اعتمدت الدراسة بصفة أساسية علي البيانات

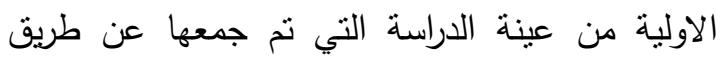

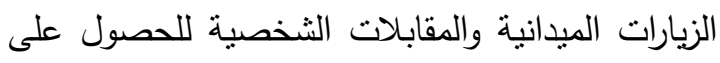
بيانات العينة التى تم اختيارها ، وتم التيارت التنيار عينة

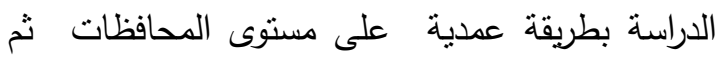
على مستوى المراكز ثم على مستوى القرى ويبلغ عدئن

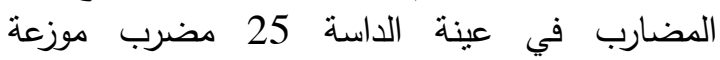
بالمناطق الاتية ثلاثة مضارب بمركز قلين بمحافظة

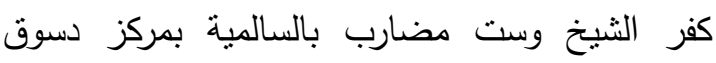
بمحافظة كفر الثيخ وثماني مضارب بمركز فوة بكفر

وثلاثة مضارب بأنياي البارود بالبحيرة وخمس الثيخ. مضارب بمراكز المحلة وقطور وطنطا بالغربية .

كيفية تسويق الارز الشعير

\section{1- - 1 - تاجر القرية}

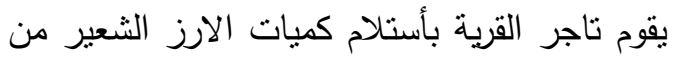

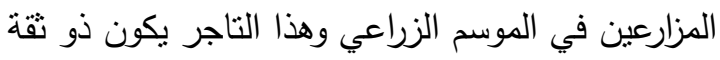

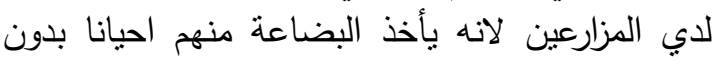

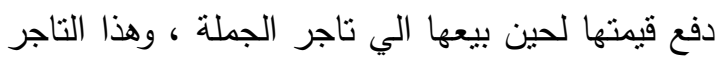

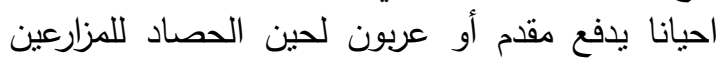

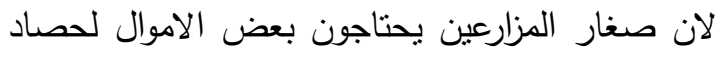

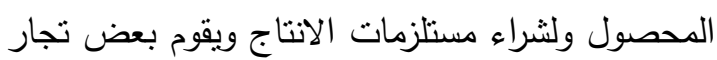

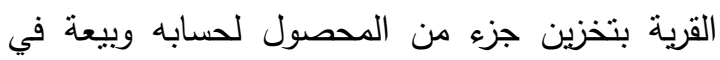
الوقت المناسب.

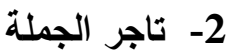

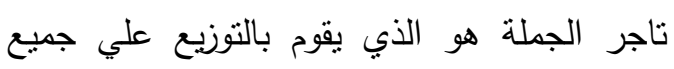

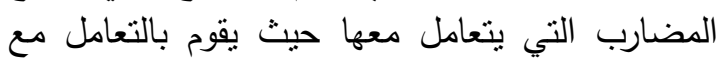

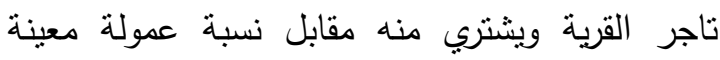

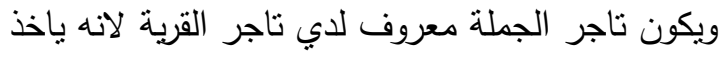

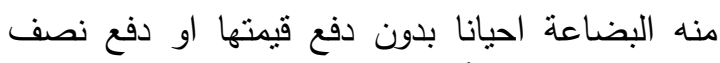

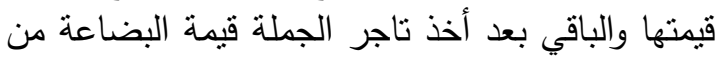
المضرب الذي يتعامل معه.
وتعتبـر تكـاليف صـــاعة ضــرب الأرز مسن أهـم

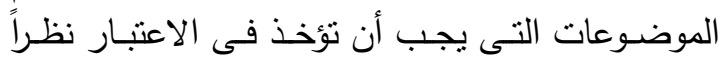

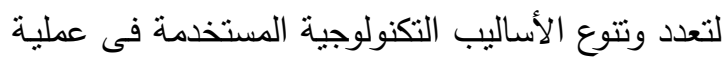

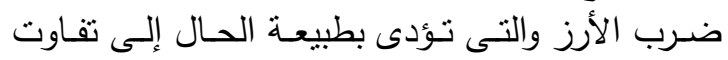

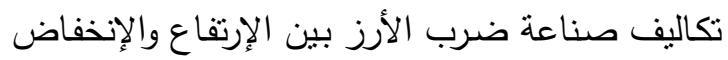

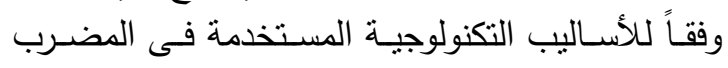

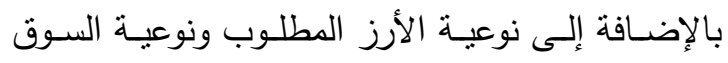
المراد توجيه الأرز المضروب نوعة الإنه.

\section{مشكلة البحث}

تنتخص المشكلة فى أن هناك إرتفاع فى تكاليف

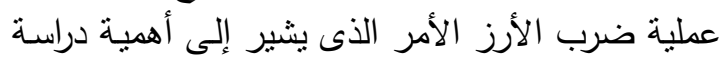

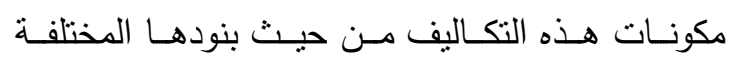

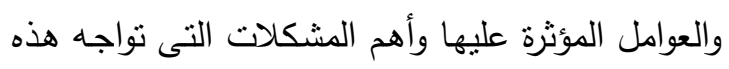

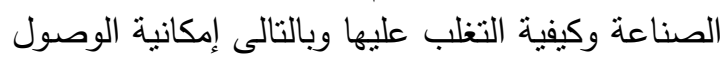

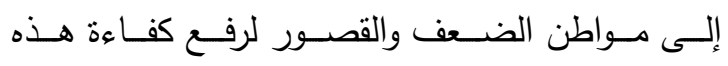

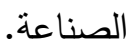

\section{هاف البحث}

يستهذف هـذا البحـث بثـكل عـام دراسـة تكـاليف

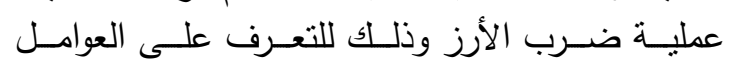

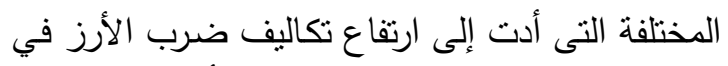

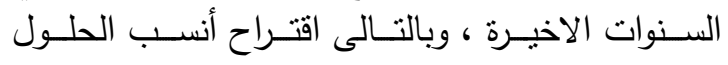
لتحسين كفاءة هذه الصناعة بما يحقق تدنية تكاليفها.

\section{الطريقة البحثية}

اعتمدت الدراسـة فـى تحقيـق أهدافها السـابقة على الإسى

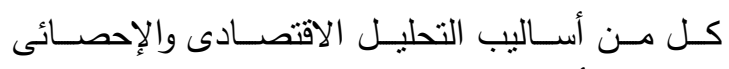

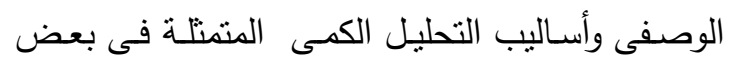
أدواته منل تحليل معادلات الإنحدار الخطى، واعنى التهدت

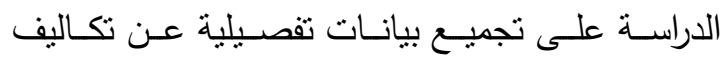

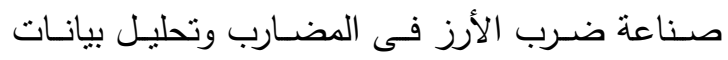

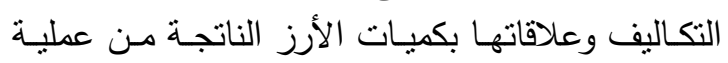

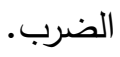


الاصفر نتيجة سوء التخزين ولا يمكن تسويقة) فيتم

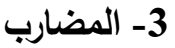

رجوعة الي التاجر مره اخري .

2- مرحلة الغزيلة

يتعامل تاجر الجملة مع عده مضارب يعرفها تماماً

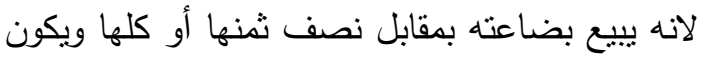

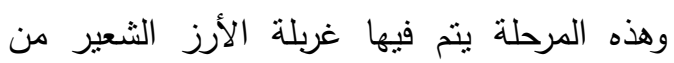

الشوائب والأتربه وذللك بواسطة هزازات مخصصة لذئل الذلك.

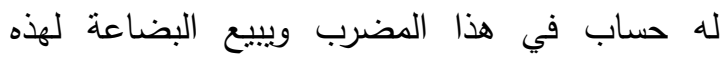

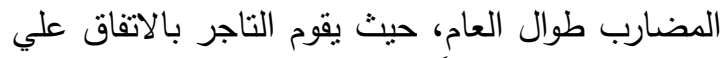

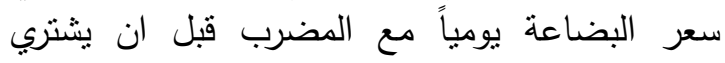

3- مرحلة التقشير

وهذه المرحلة يتم فيها تقشير أو فصل حبه الأرز

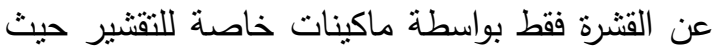

يقوم بفصل القترة عن الحبة وتذهب القشرة (السرسة) الي مسار اخر لطحنها الي سرسة ناعمة وتستخدم كعلف للمواثتي بعد الخلط مع مواد اخري.

\section{4- مرحلة التلميع أو الصنفرة}

وهذه المرحلة تتم بواسطة ماكينات خاصة لصنفرة الحبة وجعلها بيضاء لامعة ويتم اخراج الكونة (رجيع ماتهات

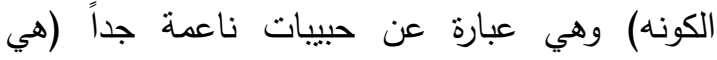
حبيبات ناتجة من تلميع حبة الارز بواسطة ماكينات

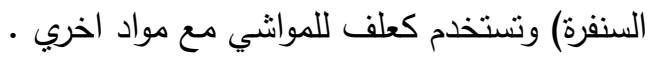

5- مرحلة غريلة الكسر

ويتم فيها غربلة الارز الابيض وفصل حبه الأرز

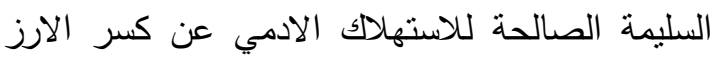

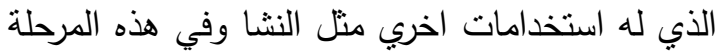
يحدد نوع الارز ونسبة الكسر وذللك عن طريق الغرابيل التي توضع بالماكينات في هذه المرحلة حيث يوجد

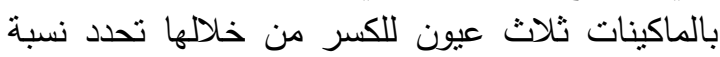

$$
\text { الكسر في الارز كالتالي : بالئ }
$$

- الارز المحلي يحدد نسبة الكسر فيه حسب المنطقة التي يوزع اليها (منطقة شعبية نسبة الكسر تكون

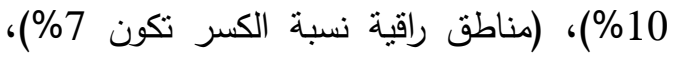

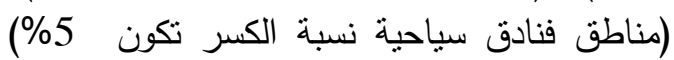
البضاعة من تاجر القرية او المزارعين. حيث البض يقوم بشراء السلعة من المصدر بفرق سعر يغطي تكاليف

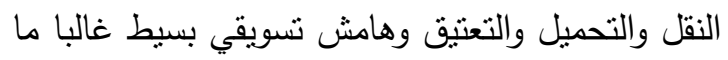
يتراوح ما بين (80-100) جنية للطن موزعة كالتالي 50 جنية لتكاليف نقل الطن ، 20 جنية تكاليف تحميل

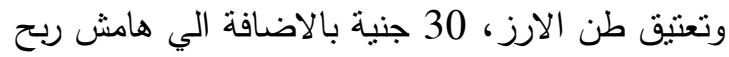

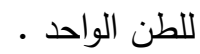
واحيانا يقوم التاجر ببيع البضاعة الي مضارب

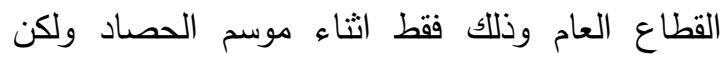
بنسبة 10\% فقط لان هذا النوع من المضارب لا نستلم

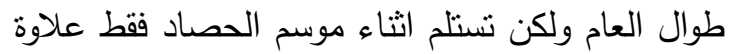
علي ذلك تستلم في وقت محدد في اليوم وليس طوال اليوم مثل القطاع الخاص بالاضافة الي تأخير ثن ثن فئن

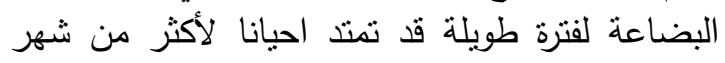

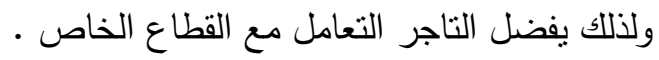

مراحل تبيض الأرز الثعير وتحويلة الي أرز أبيض

\section{1- 1 - مرحلة تنزيل الارز الثعير}

حيث يقوم العمال بتتزيل الأرز الثعير من السيارة

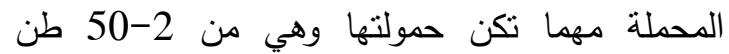
حسب حموله السيارة ويتم التنزيل بعد الفرز بواسطة من

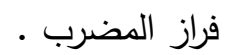

حيث يقوم بفرز شيكارة تلو الاخري ويقوم العمال بتتزيل الارز السليم وهكذا حتي يتم تفريخ لفيخ السيارة

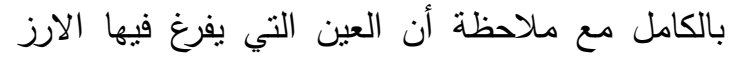

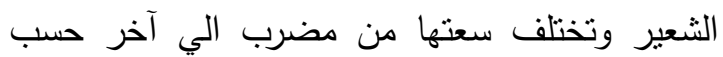
خزانات المضرب وهي تسع من 50-200 طن، بينما

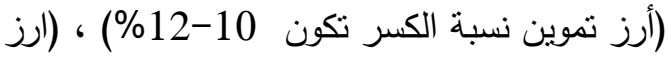
الارز غير السليم (هو ارز تغير لونة لئ الي اللون 


$$
\text { الجوهرى - العراقى - قتديل - بيومي }
$$

الابيض ويوضع علي الارز حسب طلب الثركة أو الإز

6- مرحلة جهاز السلوتكس

الجهة التي يذهب اليها الارز . الإز

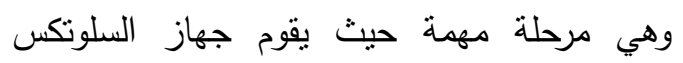

بفصل أي لون مخالف للأرز الأبيض منل الحبة 8 8 مرحلة خزان الارز

وهذه المرحلة يتم فيها تخزين الأرز الأبيض في

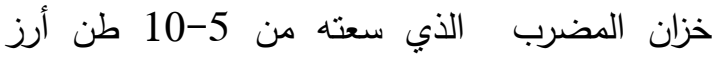

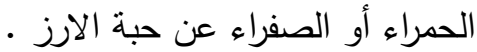

لحين تعبئة الارز في شكابير يتراوح حجمها بين 10

كجم، 25 كجم، 50 كجم حسب الارز في الطلب كما بالثكل

7- مرحلة اسطوانه الزيت البرافين

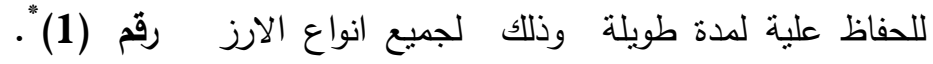

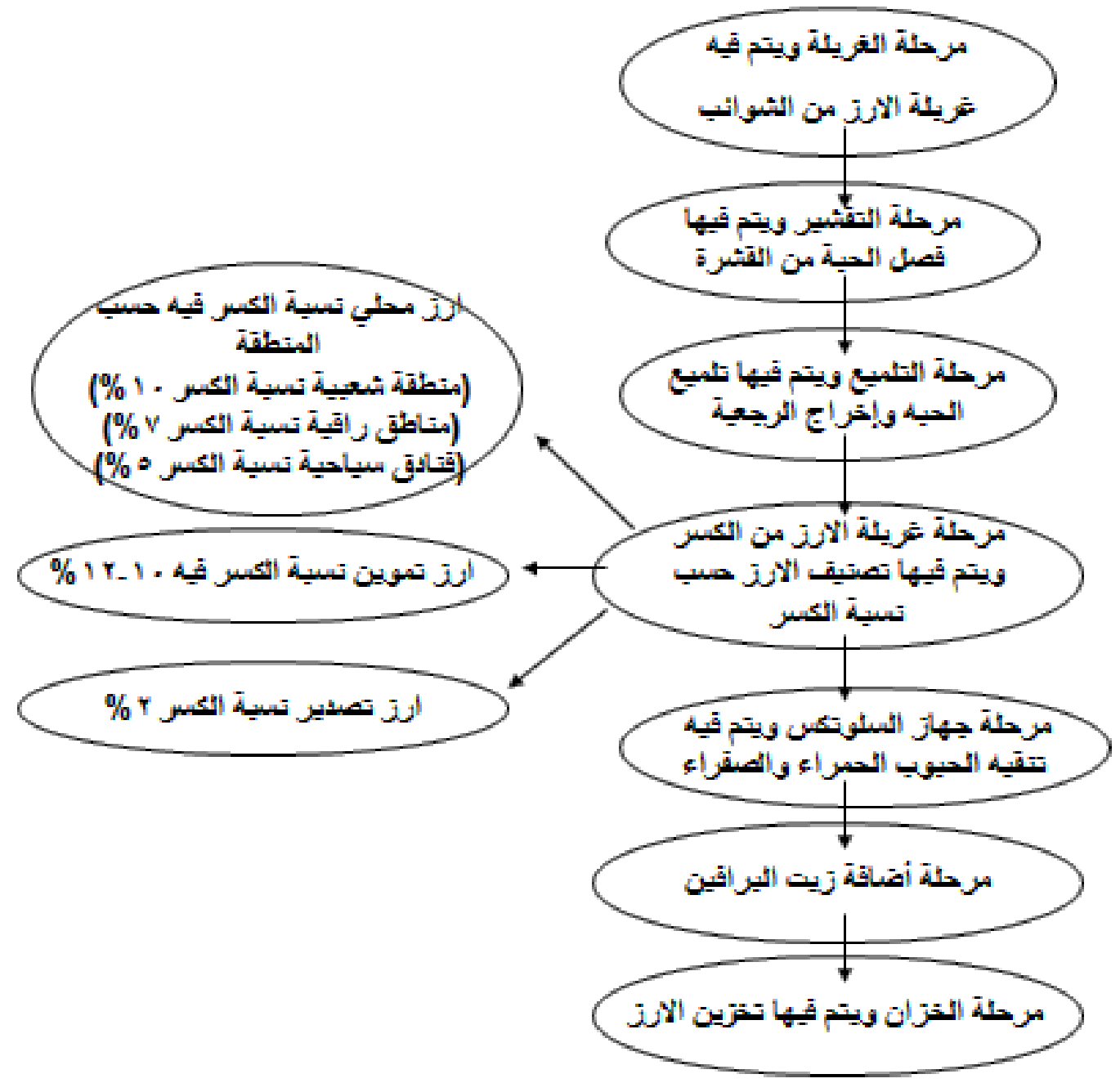

شكل رقم 1. مراحل تبيض الارز الشعير وتحويلة الي ارز ابيض 


\section{التوزيع الجغرافي للتجار بالعينة}

يبلغ عدد التجار بعينة الدراسة 26 ناجراً موزع كالاتي عشر تجار بمراكز المحلة وقطور وطنطا بالغربية وعشر تجار اليضا بمراكز قليين ودسوق والسالمية بمحافظة كفر الثيخ ،ست تجار تجار بمركز ايتاي البارود وتم اختيارهم بطريقة عمدية.

الكميات من الارز الشعير التي تم توريدها الي المضارب من التجار

يتضح من الجدول (1) ان هناك حوالي 26 تاجر

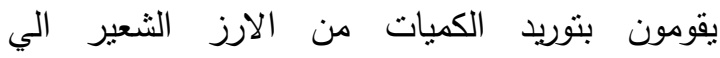
المضارب بعينة الدراسة وان متوسط الكيات الكية المنية المورده

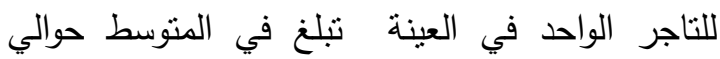

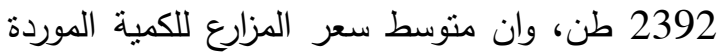
حوالي 2683 جنبة للطن، وان منان منوسط تكلفة النقل

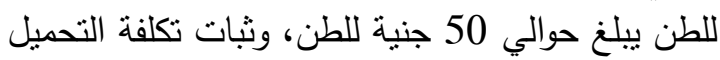

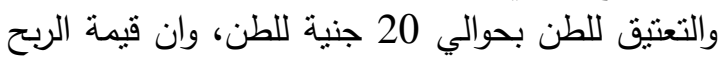

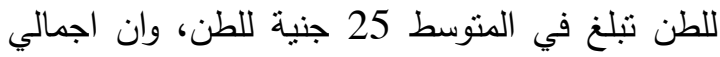
سعر المضرب وهو عبارة عن سعر المزارع مضاف اليه التكاليف والربح ويبلغ في المتوسط حوالي 2778

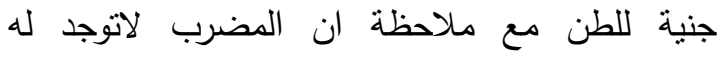

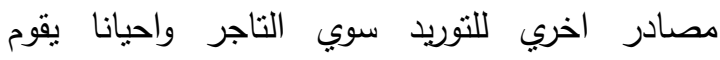

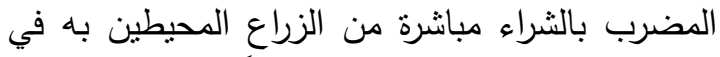

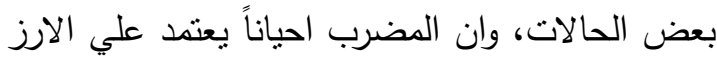

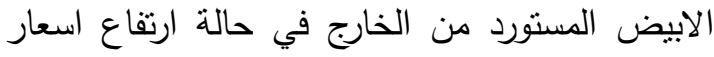

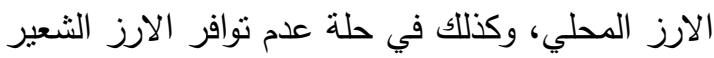

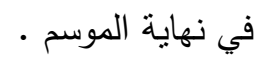
يلاحظ ان تجار العينة الموردين للارز الثعير الي

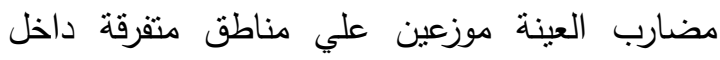

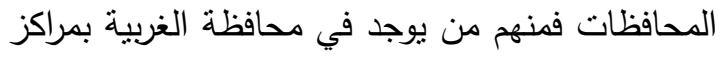

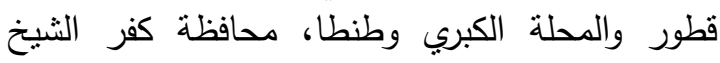
بمركز قلين، السالمية، فوة، وان التجار يقومون بتوريد

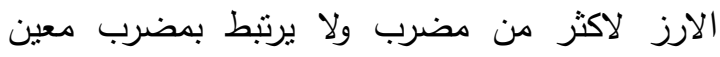

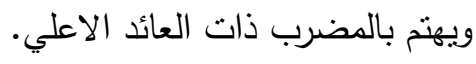

التوزيع الجغرافي للمضارب بالعينة

يبلغ عدد المضارب في عينة الدراسة 25 مضرب

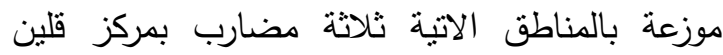

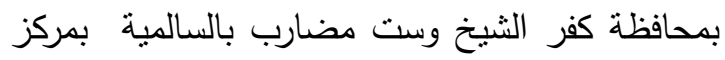
دسوق بمحافظة كفر الثيخ وثناثثة مضارب بأبات بأنياني

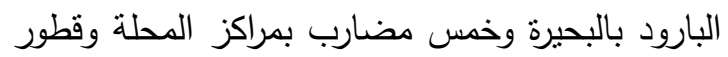

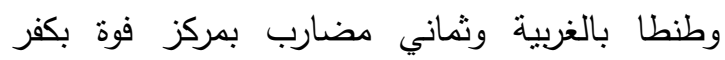
الثيخ. - مضارب مركز قلين: وهي مضارب حديثة وبها

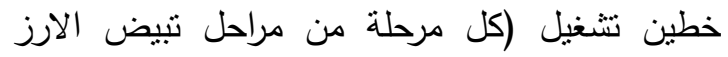

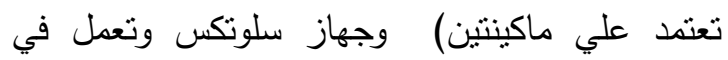

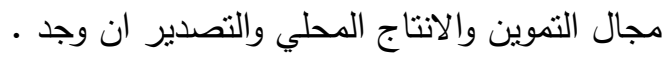

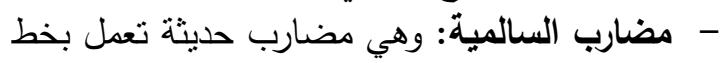

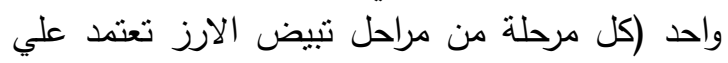

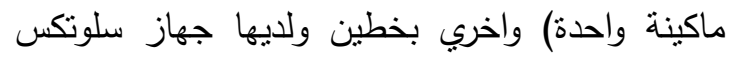

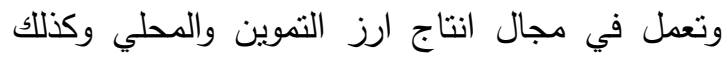

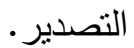
- مضارب مركز فوه: وهي مضارب حديثة وبها

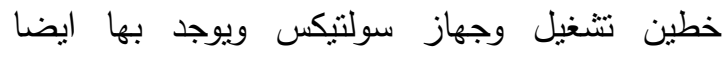

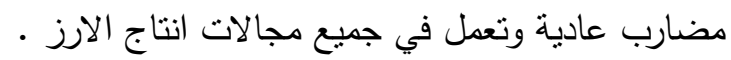

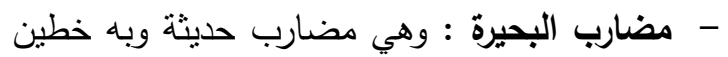

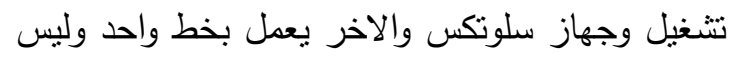

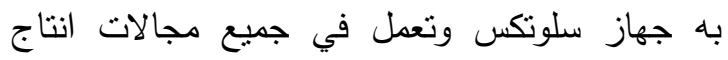

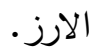
- مضارب الغزبية: وهي مضارب عادية وبه خط انتاج تتغيل واحد وليس لديها جهاز سولتيكس وتعمل

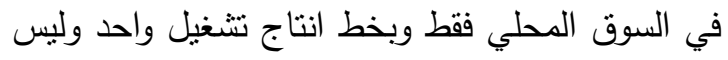

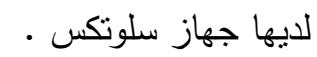
- مضارب حكومية: وهي مضارب حديثة وبها اكثر

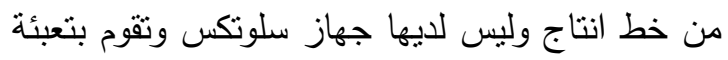

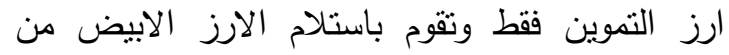

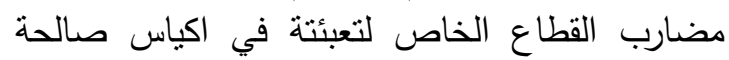

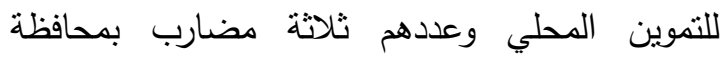

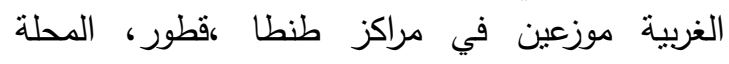

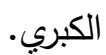




$$
\text { الجوهرى - العراقى - قنديل - بيومي }
$$

جدول 1. الكمية الني وردها النجار الي المضارب ومتوسط سعر المزارع والمضرب والربح والتكاليف لموسم 2015

\begin{tabular}{|c|c|c|c|c|c|c|}
\hline بالجنية للطن المضرب & \begin{tabular}{|l|} 
الريجة \\
\end{tabular} & والتعتيق بالجنية & النقل بالجنية & المزارع بالجنية سعر & التاجر الية التي وردها & التاجر \\
\hline 2810 & 30 & 20 & 50 & 2710 & 1100 & 1 \\
\hline 2805 & 35 & 20 & 50 & 2700 & 1200 & 2 \\
\hline 2770 & 20 & 20 & 40 & 2690 & 600 & 3 \\
\hline 2785 & 25 & 20 & 40 & 2700 & 1500 & 4 \\
\hline 2765 & 20 & 20 & 45 & 2680 & 600 & 5 \\
\hline 2765 & 35 & 20 & 40 & 2670 & 1500 & 6 \\
\hline 2750 & 40 & 20 & 40 & 2650 & 1500 & 7 \\
\hline 2780 & 30 & 20 & 40 & 2690 & 2500 & 8 \\
\hline 2775 & 35 & 20 & 40 & 2680 & 1500 & 9 \\
\hline 2790 & 20 & 20 & 50 & 2700 & 2500 & 10 \\
\hline 2815 & 25 & 20 & 50 & 2720 & 2700 & 11 \\
\hline 2820 & 20 & 20 & 50 & 2730 & 3500 & 12 \\
\hline 2835 & 35 & 20 & 50 & 2730 & 4000 & 13 \\
\hline 2850 & 40 & 20 & 60 & 2730 & 5000 & 14 \\
\hline 2820 & 30 & 20 & 60 & 2710 & 4000 & 15 \\
\hline 2820 & 35 & 20 & 45 & 2720 & 6000 & 16 \\
\hline 2760 & 20 & 20 & 40 & 2680 & 4000 & 17 \\
\hline 2780 & 20 & 20 & 50 & 2690 & 5000 & 18 \\
\hline 2755 & 30 & 20 & 55 & 2650 & 1300 & 19 \\
\hline 2805 & 35 & 20 & 50 & 2700 & 3000 & 20 \\
\hline 2745 & 25 & 20 & 50 & 2650 & 600 & 21 \\
\hline 2730 & 15 & 20 & 45 & 2650 & 900 & 22 \\
\hline 2785 & 20 & 20 & 45 & 2700 & 3000 & 23 \\
\hline 2800 & 30 & 20 & 40 & 2710 & 3500 & 24 \\
\hline 2785 & 25 & 20 & 60 & 2680 & 800 & 25 \\
\hline 2750 & 20 & 20 & 60 & 2650 & 400 & 26 \\
\hline 2778 & 25 & 20 & 50 & 2683 & 2392 & المتوسط \\
\hline
\end{tabular}

المصدر: عينة الدراسة. 
العمالة، عدم انتظام العمالة، عدم نوافر العمالة

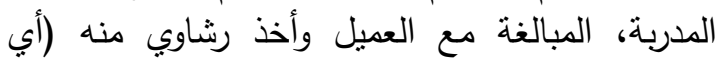
يطلب فراز المضرب بمبالغ مقابل تتزيل ارز غير غير غير العير سليم و به عيوب).

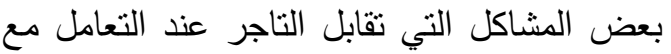
المضارب: يتضح من الدراسة الميدانية ان هناك بعض التصائ

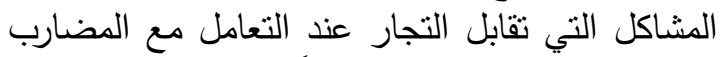

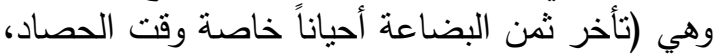

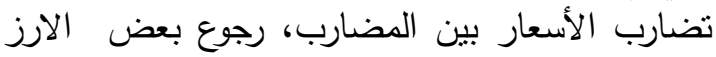

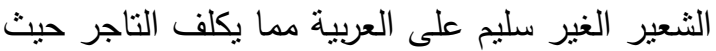

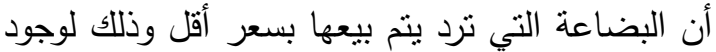

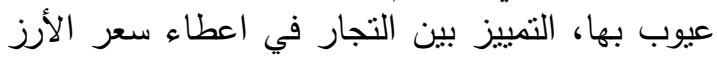
وذللك عن طريق إعطاء سعر أعلي للتاجر الذي الذي يورد الأبرد

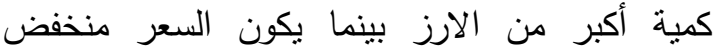
للكميات الصغيرة وهذا يكون في صالح المضرب. لئر لئر

\section{تكاليف تحويل الارز الشعير الي الاز الابيض}

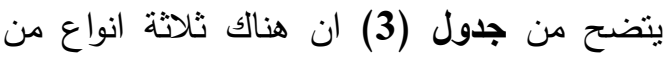

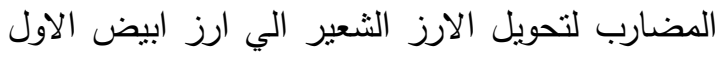

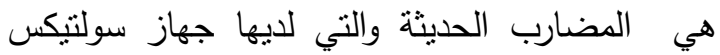
والنوع الثاني هو المضارب العادية الني ليس لديها

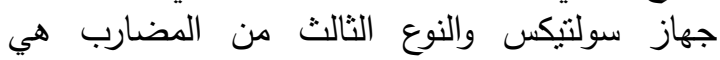
مضارب القطاع العام ويبلغ عدد المضارب الحديثة في العينة (12) مضرب بينما يبلغ عدد المضارب العارب العادية

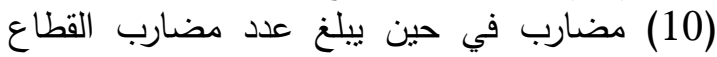

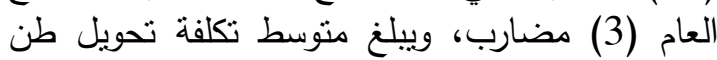
الارز الثعير الي أرز ابيض في في المضارب البناب الحديثة

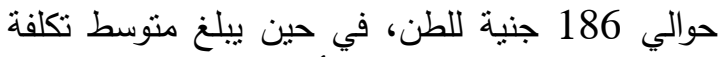

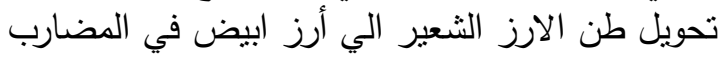

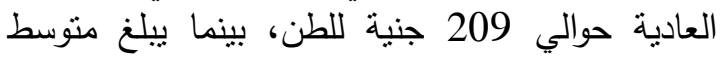

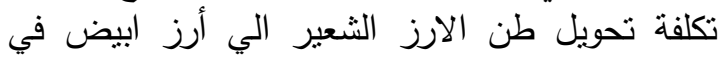

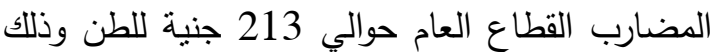
بسبب عدم فرز الارز الثعير جيداً وارتفاع اجر العمالة لطالة

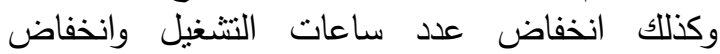

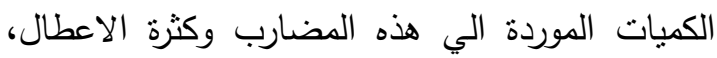

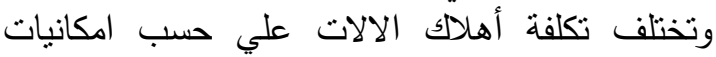

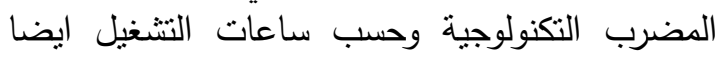
وكذللك نسبة الاعطال في المضارب.
تكاليف التخزين للارز الشعير للمضرب

يوضح من الجدول (2) أن الكمية المخزنة من الأرز الثعير تبلغ في المنوسط للمضرب الواحد حوالي 1564 طن، وان كمية الفاقد من التخزين نبلغ في في لإني المتوسط حوالي 18 طن للمضرب المن بقيمة حوالي 38

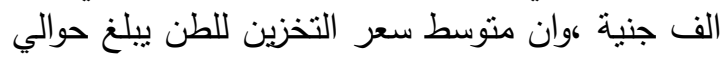
2100 جنية/طن، وان منوسط الايجار الطن لكل شهر

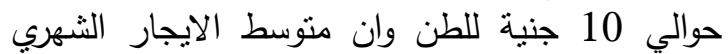

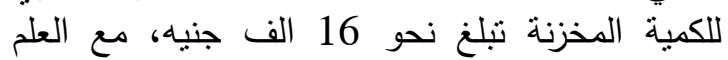
تنوقف الكمبة المخزنة علي نسبة الرطوبة في الارز

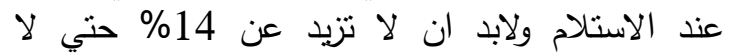

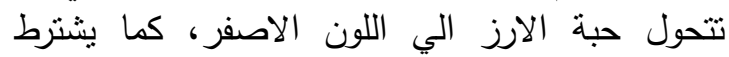

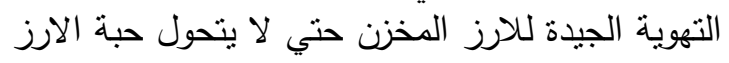

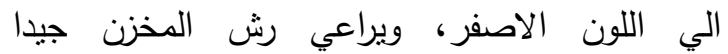

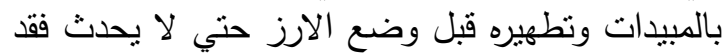

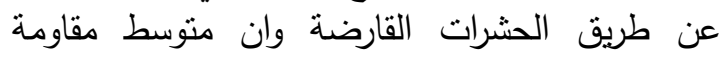
الافات التخزين للطن يبلغ حوالي 560 جنيه/طن في الفي حين أن متوسط الفائدة علي رأس المال المال حوالي 168.24 بالالف جنية للكمية المخزنة.

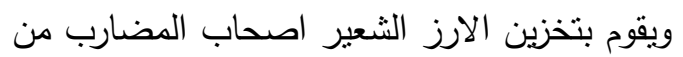

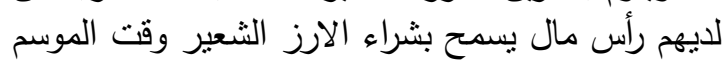

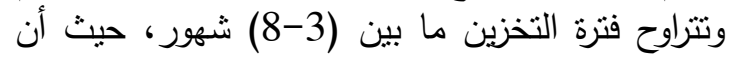
المضارب تخزن الارز لحين الطلب علية طوال

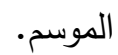

بعض المشاكل التي تقابل المضارب عند التعامل مع التجار

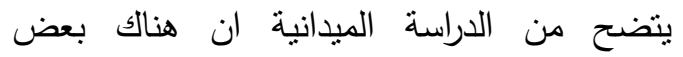

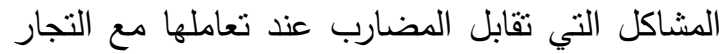

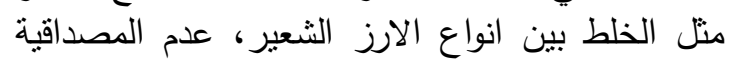

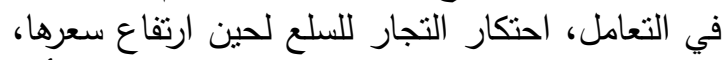

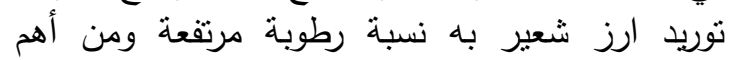

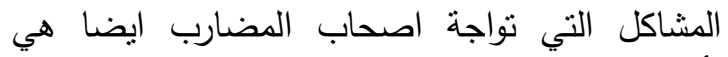

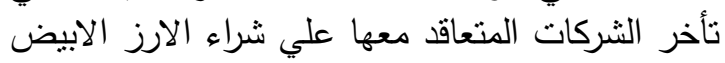

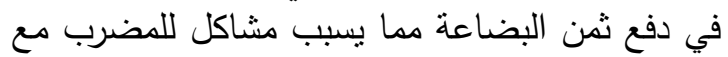

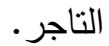

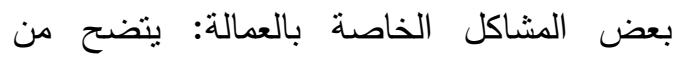

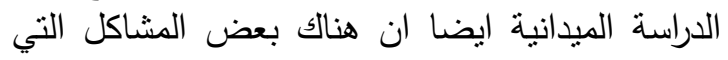

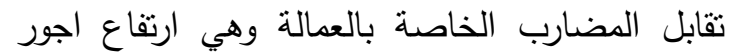




$$
\text { الجوهرى - العراقى - قنديل - بيومي }
$$

جدول 2. تكاليف التخزين للارز الشعير بالطن لموسم 2015

\begin{tabular}{|c|c|c|c|c|c|c|}
\hline بأس الفائدة علي & مقاومة الافات للاتية & الايجار الف جنية & بالالف جنيه الفاقد & كمية الفاقد & المخزنة & المضرب \\
\hline 315 & 1000 & 30 & 63.0 & 30 & 3000 & 1 \\
\hline 210 & 700 & 20 & 42.0 & 20 & 2000 & 2 \\
\hline 262.5 & 850 & 25 & 52.5 & 25 & 2500 & 3 \\
\hline 52.5 & 200 & 5 & 10.5 & 5 & 500 & 4 \\
\hline 165 & 500 & 15 & 31.5 & 15 & 1500 & 5 \\
\hline 110 & 350 & 10 & 21.0 & 10 & 1000 & 6 \\
\hline 42 & 150 & 4 & 12.6 & 6 & 400 & 7 \\
\hline 262.5 & 850 & 25 & 52.5 & 25 & 2500 & 8 \\
\hline 315 & 1000 & 30 & 63.0 & 30 & 3000 & 9 \\
\hline 110 & 400 & 10 & 31.5 & 15 & 1000 & 10 \\
\hline 77 & 200 & 7 & 21.0 & 10 & 700 & 11 \\
\hline 88 & 250 & 8 & 23.1 & 11 & 800 & 12 \\
\hline 161 & 500 & 14 & 58.8 & 28 & 1400 & 13 \\
\hline 165 & 600 & 15 & 46.2 & 22 & 1500 & 14 \\
\hline 110 & 400 & 10 & 31.5 & 15 & 1000 & 15 \\
\hline 77 & 300 & 7 & 21.0 & 10 & 700 & 16 \\
\hline 52.5 & 200 & 5 & 21.0 & 10 & 500 & 17 \\
\hline 33 & 150 & 3 & 12.6 & 6 & 300 & 18 \\
\hline 262.5 & 900 & 25 & 52.5 & 25 & 2500 & 19 \\
\hline 210 & 700 & 20 & 42.0 & 20 & 2000 & 20 \\
\hline 315 & 1100 & 30 & 63.0 & 30 & 3000 & 21 \\
\hline 210 & 800 & 20 & 42.0 & 20 & 2000 & 22 \\
\hline 402.5 & 1200 & 35 & 73.5 & 35 & 3500 & 23 \\
\hline 110 & 400 & 10 & 31.5 & 15 & 1000 & 24 \\
\hline 88 & 300 & 8 & 33.6 & 16 & 800 & 25 \\
\hline 168.24 & 560 & 16 & 38 & 18 & 1564 & المتوسط \\
\hline
\end{tabular}


جدول 3. يوضح تكلفة تحويل الارز الشعير الي الارز الابيض بالجنية للطن لموسم 2015

\begin{tabular}{|c|c|c|c|c|c|c|c|c|}
\hline جنية الضربة & اجلاك" الالات تكلة & جنية /طن & الشكاير & زيت البرافين & جنية /طنة العمالة & الكمية الموردة & المضرب & | المضرب \\
\hline 185 & 10 & 35 & 50 & 40 & 50 & 10000 & 1 & \\
\hline 175 & 10 & 35 & 50 & 40 & 40 & 9000 & 2 & \\
\hline 180 & 10 & 40 & 50 & 40 & 40 & 8000 & 3 & $\xi_{0}$ \\
\hline 180 & 10 & 30 & 50 & 50 & 40 & 7000 & 4 & E: \\
\hline 200 & 10 & 30 & 60 & 50 & 50 & 5000 & 5 & \\
\hline 200 & 10 & 40 & 60 & 50 & 40 & 4000 & 6 & $\varnothing$ \\
\hline 190 & 10 & 30 & 60 & 50 & 40 & 6000 & 7 & E \\
\hline 190 & 10 & 30 & 60 & 40 & 50 & 13000 & 8 & $E^{2}$ \\
\hline 180 & 10 & 30 & 50 & 50 & 40 & 11000 & 9 & $r$ \\
\hline 195 & 10 & 35 & 60 & 40 & 50 & 7000 & 10 & {[} \\
\hline 180 & 10 & 30 & 50 & 50 & 40 & 9000 & 11 & 8 \\
\hline 180 & 10 & 30 & 50 & 50 & 40 & 8000 & 12 & \\
\hline 186 & 10 & 33 & 54 & 46 & 43 & 8083 & المتوسط & \\
\hline 202 & 12 & 40 & 60 & 40 & 50 & 3000 & 13 & \\
\hline 197 & 12 & 35 & 60 & 50 & 40 & 5000 & 14 & E \\
\hline 197 & 12 & 35 & 50 & 50 & 50 & 4000 & 15 & $\xi$ \\
\hline 212 & 12 & 35 & 60 & 55 & 50 & 5000 & 16 & ๖. \\
\hline 212 & 12 & 40 & 50 & 50 & 60 & 3000 & 17 & $\Phi$ \\
\hline 212 & 12 & 50 & 50 & 40 & 60 & 2000 & 18 & c \\
\hline 212 & 12 & 40 & 60 & 40 & 60 & 2000 & 19 & E \\
\hline 222 & 12 & 40 & 60 & 50 & 60 & 2500 & 20 & $\frac{5}{5}$ \\
\hline 212 & 12 & 40 & 60 & 40 & 60 & 3000 & 21 & i[ \\
\hline 212 & 12 & 40 & 50 & 50 & 60 & 2000 & 22 & $\bar{\xi}$. \\
\hline 209 & 12 & 39.5 & 56 & 46.5 & 55 & 3150 & المتوسط & \\
\hline 213 & 13 & 40 & 60 & 40 & 60 & 3000 & 23 & $b^{2}$ \\
\hline 213 & 13 & 40 & 60 & 50 & 50 & 5000 & 24 & fr \\
\hline 213 & 13 & 40 & 50 & 50 & 60 & 2000 & 25 & i \\
\hline 213 & 13 & 40 & 57 & 47 & 57 & 3333 & المتوسط & 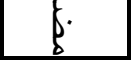 \\
\hline
\end{tabular}

المصدر : عينة الدراسة

* ) يتم حساب تكلفة الاهلاك الالات وذلك عن طريق كمية الارز الثعير التي يتم ضربها خلال العام داخل المضرب حيث

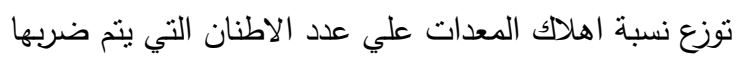


حوالي 315 طن من متوسط الكمية الموردة وبنسبة

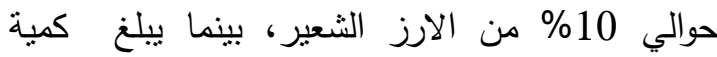

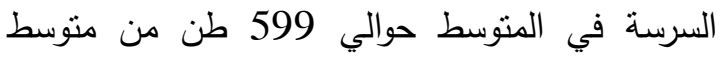

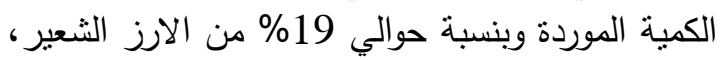
وان كمية الثوائب والاتربة تبلغ في المتوسط حوالئ

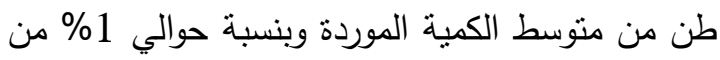

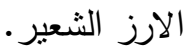

وان متوسط الكمية المورده من الارز الثعبر الي المضارب الحكومية نحو 3333 طن ويكون نواتج الأنج

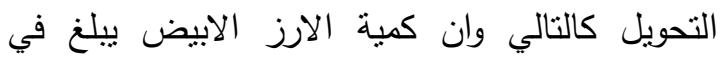
المتوسط حوالي 2200 طن من متوسط الكمية الموردة الإنة

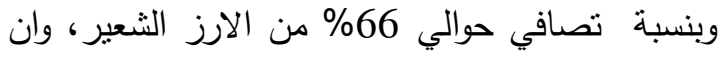

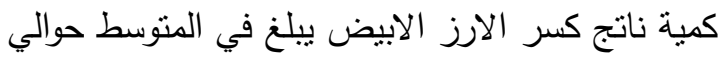
133 طن من منوسط الكمية الموردة وبنسبة حوالي

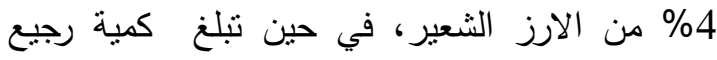
الكون في المتوسط حوالي 333 طن من متوسط الكنية

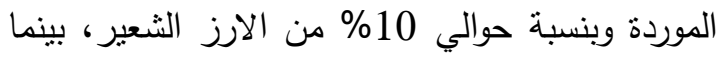

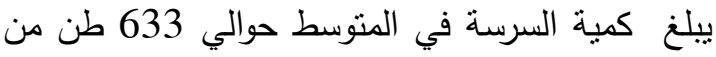

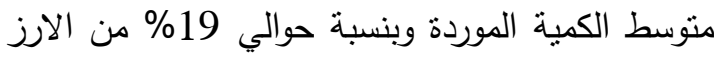

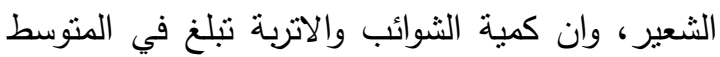

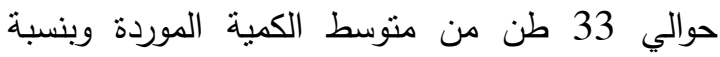
حوالي 1\% من الارز الشعير . ويلاحظ ان اذ زادت نسبة الكسر في الارز الإنيض الكبر

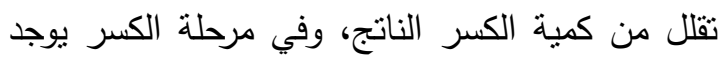

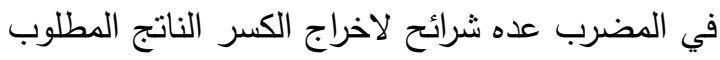

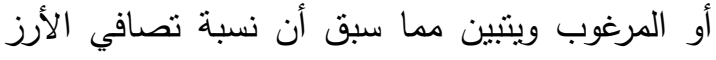

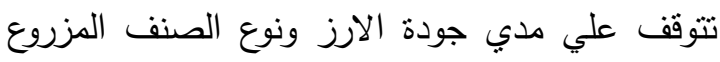

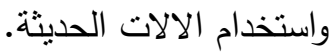

نواتج تحويل الارز الثعير الي الاز الابيض

بتضح من جدول (4) أن منوسط الكمية المورده

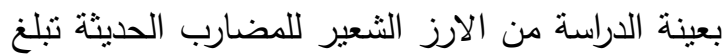

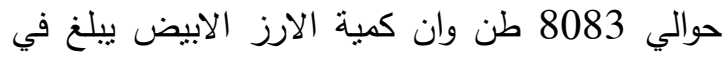

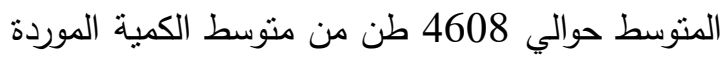

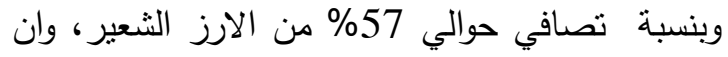
كمية ناتج كسرالارز الابيض يبلغ في المنتوسط حوالي

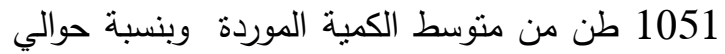
13 من الارز الثعير، في حين نبلغ كمية رجيع

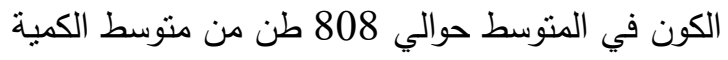

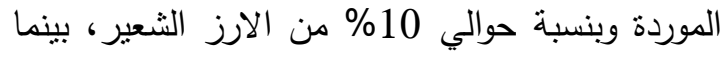

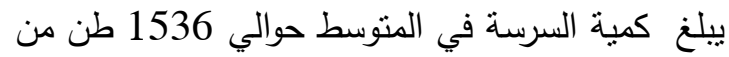

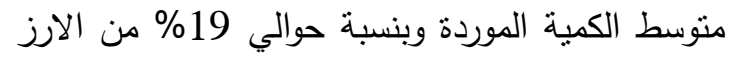

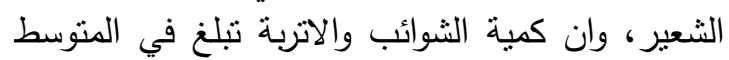

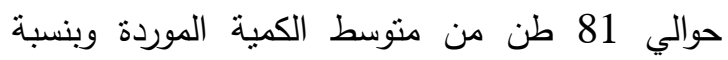

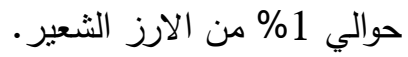
في حين متوسط الكمية المورده من الارز الثيرة الثعير

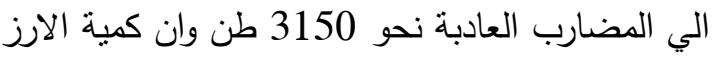

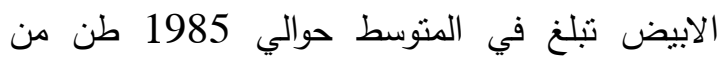

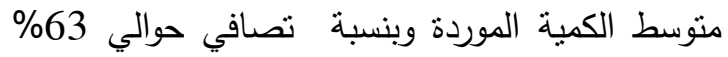

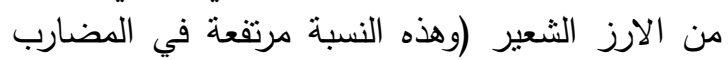
العادية وذلك لان لان هذه المضارب تعمل في مجال التموين بكثرة والسوق المحلي الموجة للمناطق الشعبية

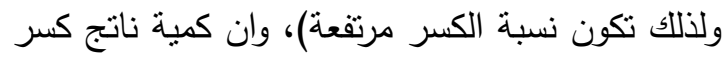

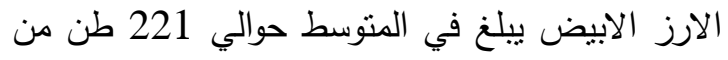

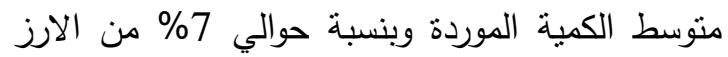

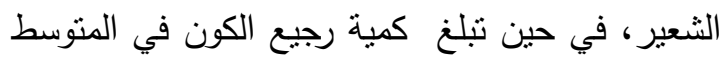


جدول 4. يوضح نواتج تحويل الارز الشعير الي الارز الابيض للطن

\begin{tabular}{|c|c|c|c|c|c|c|c|}
\hline الشوائب & السرسة & بالطن & كسر ارز & ارز ابيض & لكارز الشعبة الموردة & المضرب & المضرب \\
\hline 100 & 1900 & 1000 & 1300 & 5700 & 10000 & 1 & \multirow{13}{*}{ 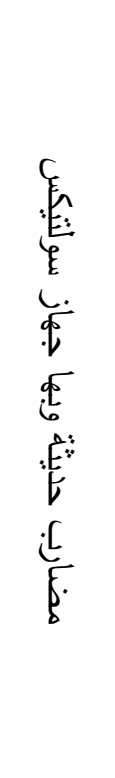 } \\
\hline 90 & 1710 & 900 & 1170 & 5130 & 9000 & 2 & \\
\hline 80 & 1520 & 800 & 1040 & 4560 & 8000 & 3 & \\
\hline 70 & 1330 & 700 & 910 & 3990 & 7000 & 4 & \\
\hline 50 & 950 & 500 & 650 & 2850 & 5000 & 5 & \\
\hline 40 & 760 & 400 & 520 & 2280 & 4000 & 6 & \\
\hline 60 & 1140 & 600 & 780 & 3420 & 6000 & 7 & \\
\hline 130 & 2470 & 1300 & 1690 & 7410 & 13000 & 8 & \\
\hline 110 & 2090 & 1100 & 1430 & 6270 & 11000 & 9 & \\
\hline 70 & 1330 & 700 & 910 & 3990 & 7000 & 10 & \\
\hline 90 & 1710 & 900 & 1170 & 5130 & 9000 & 11 & \\
\hline 80 & 1520 & 800 & 1040 & 4560 & 8000 & 12 & \\
\hline 81 & 1536 & 808 & 1051 & 4608 & 8083 & المتوسط & \\
\hline 30 & 570 & 300 & 210 & 1890 & 3000 & 13 & \multirow{11}{*}{ 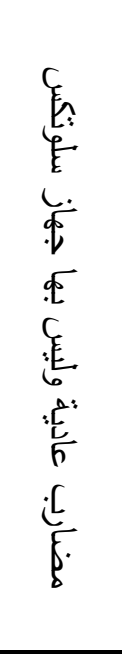 } \\
\hline 50 & 950 & 500 & 350 & 3150 & 5000 & 14 & \\
\hline 40 & 760 & 400 & 280 & 2520 & 4000 & 15 & \\
\hline 50 & 950 & 500 & 350 & 3150 & 5000 & 16 & \\
\hline 30 & 570 & 300 & 210 & 1890 & 3000 & 17 & \\
\hline 20 & 380 & 200 & 140 & 1260 & 2000 & 18 & \\
\hline 20 & 380 & 200 & 140 & 1260 & 2000 & 19 & \\
\hline 25 & 475 & 250 & 175 & 1575 & 2500 & 20 & \\
\hline 30 & 570 & 300 & 210 & 1890 & 3000 & 21 & \\
\hline 20 & 380 & 200 & 140 & 1260 & 2000 & 22 & \\
\hline 32 & 599 & 315 & 221 & 1985 & 3150 & المتوسط & \\
\hline 30 & 570 & 300 & 120 & 1980 & 3000 & 23 & \multirow{4}{*}{ 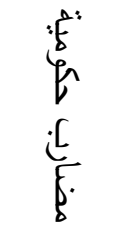 } \\
\hline 50 & 950 & 500 & 200 & 3300 & 5000 & 24 & \\
\hline 20 & 380 & 200 & 80 & 1320 & 2000 & 25 & \\
\hline 33 & 633 & 333 & 133 & 2200 & 3333 & المتوسط & \\
\hline
\end{tabular}

المصدر: عينة الدراسة 
اولاً: دالة تكاليف ضرب الارز الابيض للمضارب الحديثة بعينة الاراسة

بتقدير معالم دالة التكاليف الكلية (T.C) لإنتاج

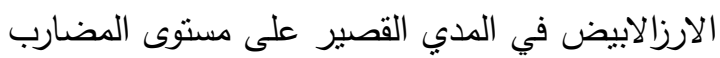

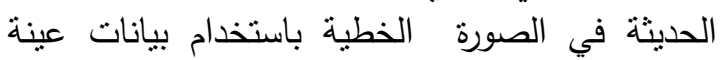

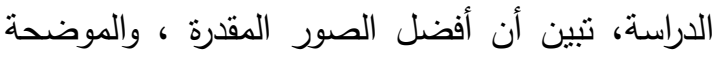

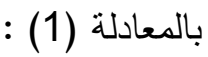

$$
\text { T.C }=34.5+177.5 Q
$$$$
\text { (1.05) }(26.09)^{*} \text { * }
$$

$$
\mathbf{R}^{2}=0.99 \quad \mathbf{F}=681.1
$$

وتوضح دالة التكاليف الكلية (T.C) لضرب الارز

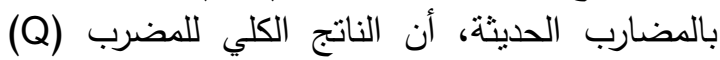

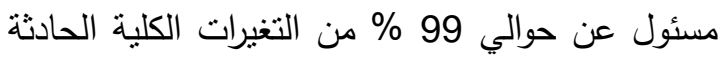

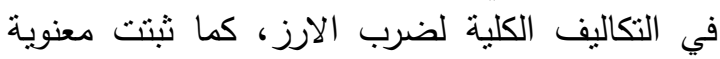

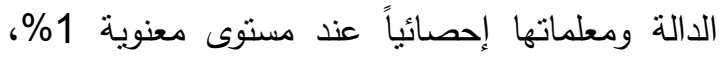

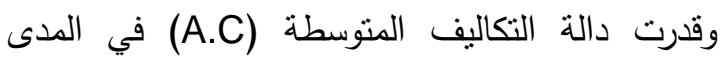
القصير من خلال قسمة دالة التكاليف الكلية (T.C)

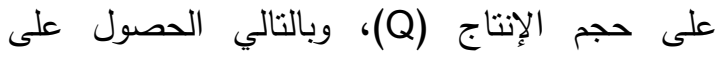
المعادلة (2):

$$
A . C=34.5 / Q+177.5
$$

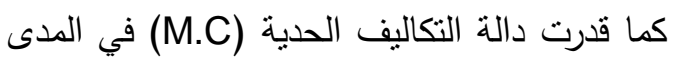

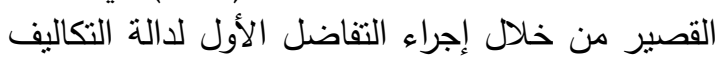

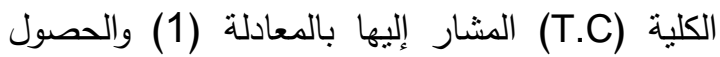
على دالة التكاليف الحدية الموضحة بالمعادلة (3):
دوال تكاليف ضرب الازز بعينة الدراسة يتتاول هذا الجزء التقدير الإحصائي لدوال تكاليف

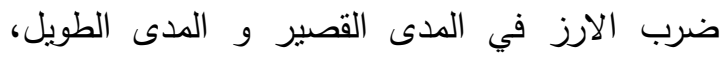

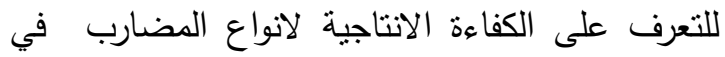

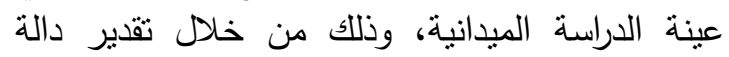
التكاليف الكلية (T.C) ثم اثنقاق دوال التكاليف الحدية (M.C) والتكاليف المتوسطة (A.C)، وكذلك التعرف (T.C)

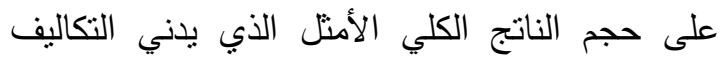

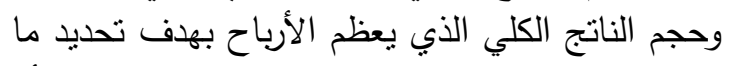

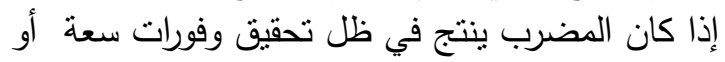

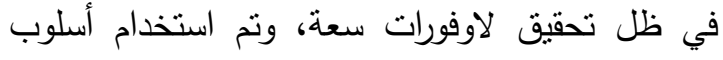
الانحدار الخطي في الصورة التربيعية والتكعيبية لتقدير

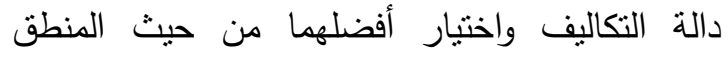
الاقتصادي والمعنوية الاحصائية، وتعبر دالة التكالية التاليف الانتاجية عن طبيعة العلاقة بين التكاليف الكلية

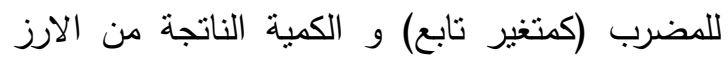

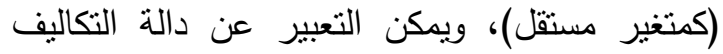
الكلية (T.C) في الصورة التالية : (دالة التكاليف في المدى القصير) :

$$
\begin{aligned}
& \text { T.C } i=\alpha+\beta_{1} \mathrm{Q}_{i}+\beta_{2} \mathrm{Q}_{i}{ }^{2} \\
& \mathrm{~T} . \mathrm{C}=\alpha+\beta_{1} \mathrm{Q}_{i}+\beta_{2} \mathrm{Q}_{i}{ }^{2}+\beta_{3} \mathrm{Q}_{i}{ }^{3}
\end{aligned}
$$
(دالة التكاليف في المدى الطويل) $\mathrm{T} . \mathrm{C}_{i}=\beta_{1} \mathrm{Q}_{i}+\beta_{2} \mathrm{Q}_{i}{ }^{2}$ T.C $=\beta_{1} \mathrm{Q}_{i}-\beta_{2} \mathrm{Q}_{i}{ }^{2}+\beta_{3} \mathrm{Q}_{i}{ }^{3}$

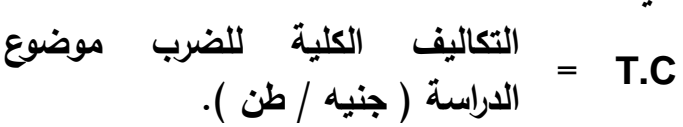

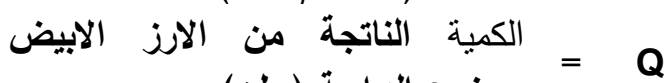

$$
\begin{aligned}
& \text { موضوع الاراسة ( طن). }
\end{aligned}
$$

$M . C=177.5$ 
1783 تكاليف صناعة ضرب الأرز فى مصر

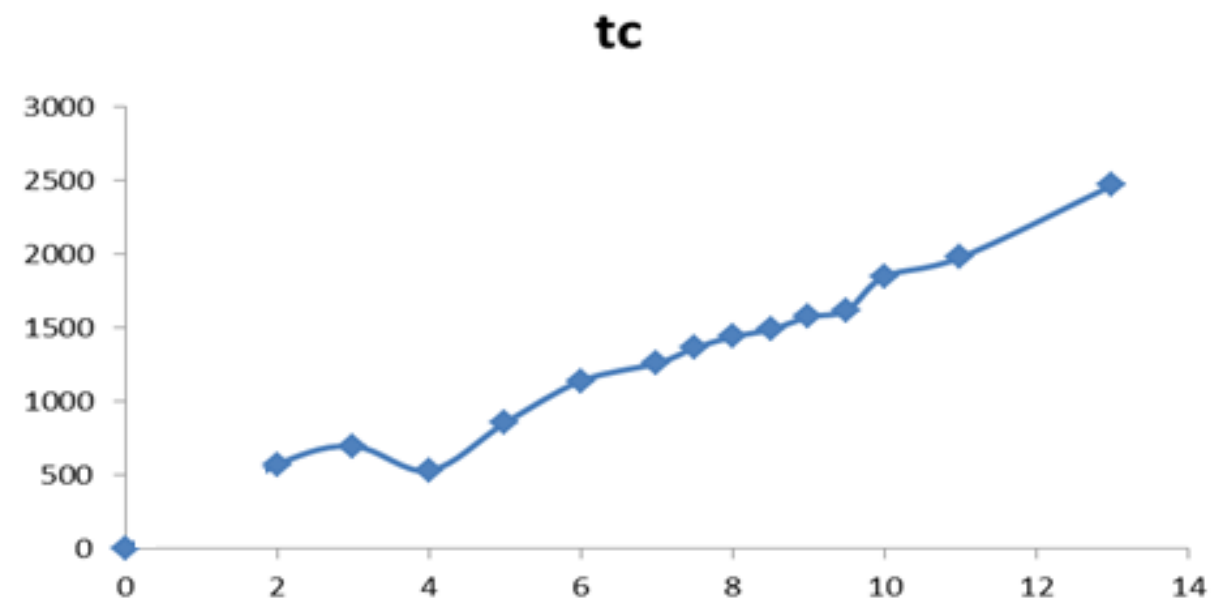

شكل 2. تكاليف ضرب الارزالابيض للمضارب الحديثة بعينة الدراسة

ويتبين من جدول (5) أن التكاليف الثابتة للطن، وبلغت التكاليف المتوسطة حوالي 185 جنيه

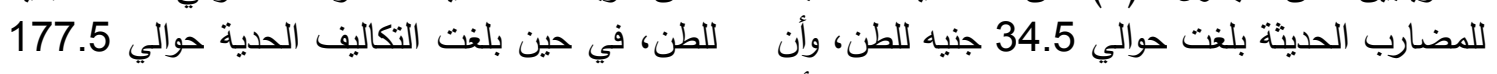

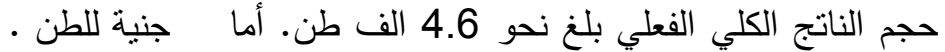
بالنسبة للتكاليف المتغيرة فقد بلغ حوالي 816.5 جنيه

جدول 5. المشتقات الاقتصادية لدوال التكاليف الانتاجية لمحصول الارز لكل من المضارب الحديثة والعادية والمجمعة بعينة الدراسة لمحافظة الغربية

\begin{tabular}{|c|c|c|c|}
\hline المضارب & المضارب & الحضارب الحيثة & 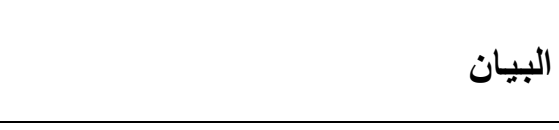 \\
\hline 3.42 & 1.9 & 4.6 & حجم الناتج الكلي الفعلي الف طن) \\
\hline 60.4 & 24.4 & 34.5 & التكاليف الثابتة \\
\hline 592.3 & 386.5 & 816.5 & التكاليف المتغيرة \\
\hline 173.2 & 195.2 & 177.5 & التكاليف الحـدية (M.C) (جنيه/ طن ) \\
\hline 190.9 & 207.5 & 185 & التكاليف المتوسطة (A.C) (جنيه/ طن ) \\
\hline
\end{tabular}

* تم تقدير قيمة التكاليف المتغيرة والتكاليف المتوسطة المصدر : جمعت وحسبت من بيانات الاستبيان الخاص باص

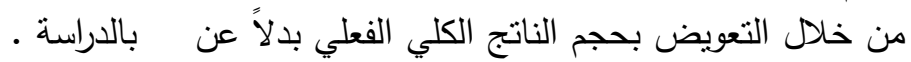
في دالة التكاليف المتغيرة (V.C) ودالة التكاليف المتوسطة (A.C) 


$$
\text { الجوهي - العراقى - قنديل - بيومي }
$$

معنوية الدالة ومعلماتها إحصائيًا عند مستوى معنوية

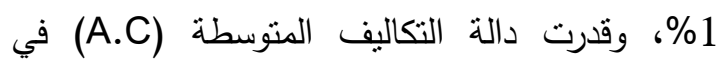
الددى القصير من خلال قسمة دالة التكاليف الكلية (T.C)

على المعادلة (2):

$$
A . C=24.4 / Q+195.2
$$

كما قدرت دالة التكاليف الحدية (M.C) في المدى الإل

القصير من خلال إجراء التفاضل الأول لدالة التكاليف التيف

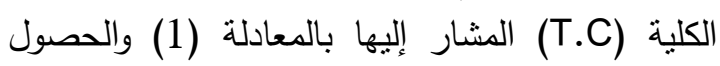
على دالة التكاليف الحدية الموضحة بالمعادلة (3):

$M . C=195.2$

(3) T.C

ويتبين من جدول (5) أن التكاليف الثابتة اللمضارب العادية بلغت حوالي 24.4 جنيه للطن ، وأن النية

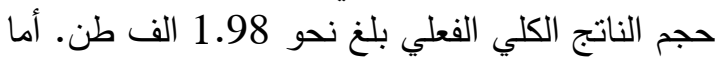
بالنسبة للنكاليف المتغيرة فقد بلغ حوالي 386.5 جنبه للطن، وبلغت النكاليف المتوسطة حوالي 207.5 جنيه للطن، في حين بلغت النكاليف الحدية حوالي 195.2

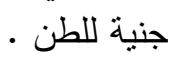

ثانياً: دالة تكاليف ضرب الازذ للمضارب العادية بعينة الدراسة

بتقدير معالم دالة التكاليف الكلية (T.C) لإنتاج

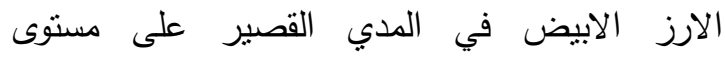
المضارب العادية في الصورة الخطية باستخدام بيانات

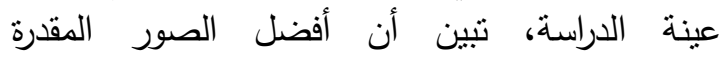
والموضحة بالمعادلة (1) :

$$
\text { T.C }=24.4+195.2 Q
$$$$
\text { (1.6) } \quad(26.03) * *
$$

$\mathbf{R}^{2}=0.99 \quad \mathbf{F}=677.4$

$$
\text { الابيض على مستوى المضارب العادية. }
$$

الكمية الناتجة من الازز الابيض (طن) العارية.

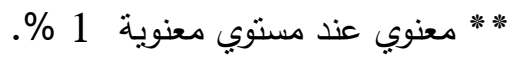

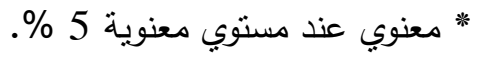

وتوضح دالة النكاليف الكلية (T.C) لضرب الارز

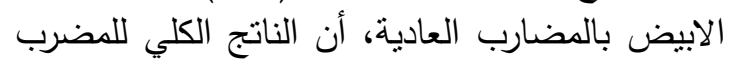

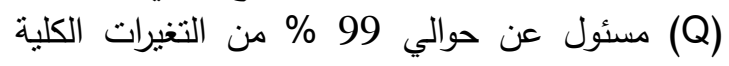
الحادثة في التكاليف الكلية لضرب الارز، كما ثنت اليت

tc

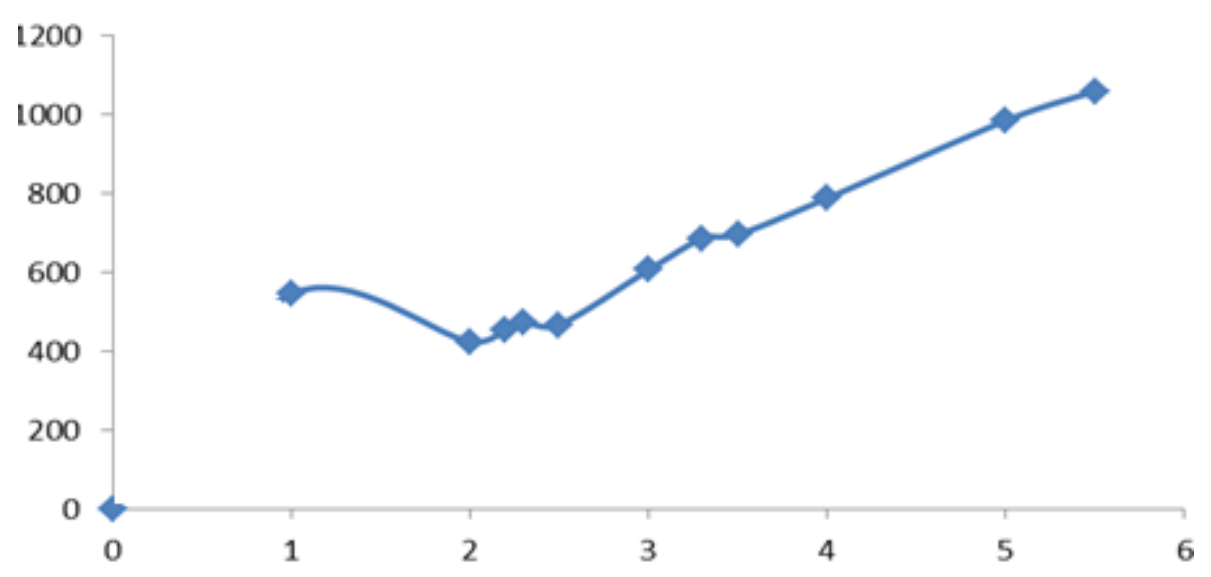

شكل 3. تكاليف ضرب الارز للمضارب العادية بعينة الدراسة 


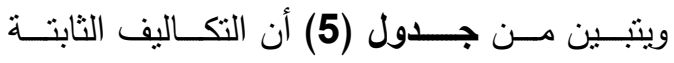

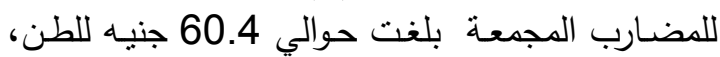

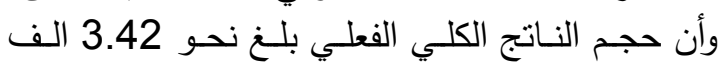

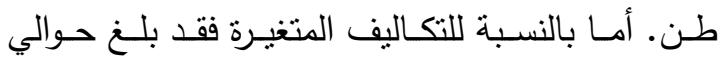

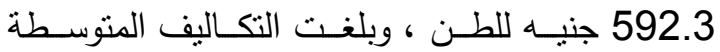

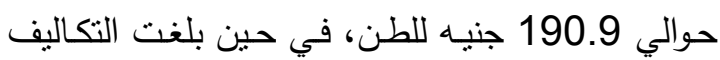
الحدية حوالي 173.2 جنية للطن .

التوصيات

1) مساعدة الثركات التي تتعامل مع المضارب في الارز الابيض بضخ مبالغ مالية بدون فوائد حتي لتي

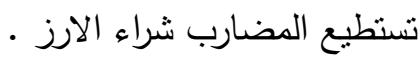

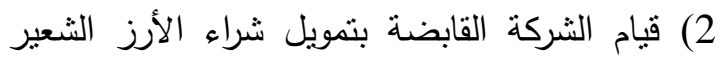
لحين قيام الثركات بيعة مستقبلاً بأسعار مناسبة لأنساء حتى لا تضطر الثركات لبيعة بأسعار تقل عن باستة

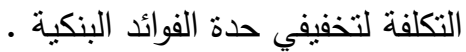

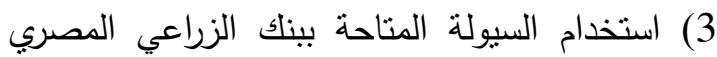

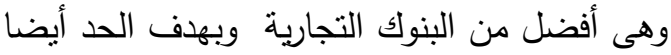

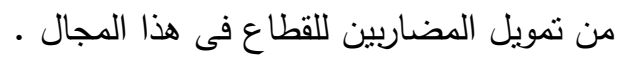

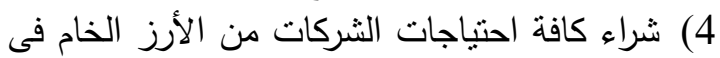

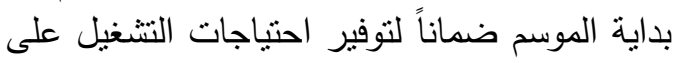

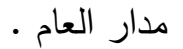
5) التزام شركات المضارب بعدم المضاربة فيما بينها

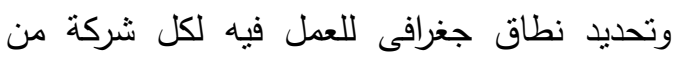
التسيق الجيد بينهما . 6) وجود جهاز تسويق كفي من قبل الدولة لتحديد

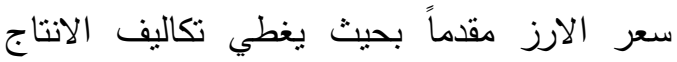

$$
\text { ويعطي له هامش ربح. }
$$

7) تزويد مضارب القطاع العام بالسيولة النقدية لشراء

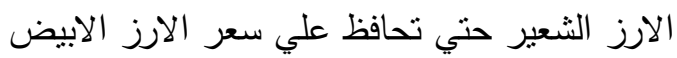

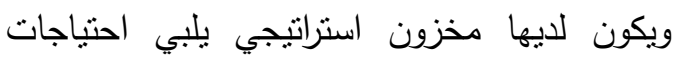
8التموين والسوق المحلي طول الموسم.

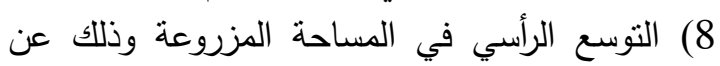
طريق استتباط اصناف محسنة في نراكز البحوث

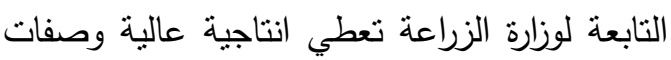

ثالثا: دالة تكاليف ضرب الارز المجمعة بعينة الدراسة بتقدير معالم دالة التكاليف الكلية (T.C) لإنتاج الارز الابيض في مستوى مضارب العينة في الصورة الإنة الخطية باستخدام بيانات عينة الدراسة، تبين أن أفضل الإبل

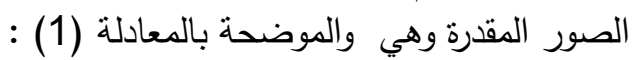

$$
T . C=60.4+173.2 Q
$$

$$
(4.4)^{*}(48.6) \text { ** }
$$

$\mathbf{R}^{2}=0.99$

$$
F=2360
$$

T.C الابيض على مستوى المضارب.

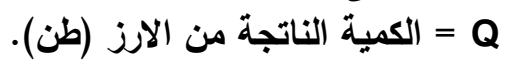

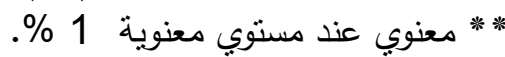
* معنوي عند مستوي معنوية 5 \% مغنوية

وتوضح دالة التكاليف الكلية (T.C) لضرب الارز الابيض بالمضارب ،حيث أن الناتج الكلي للمضرب مسئول عن حوالي 99 \% من التغئ التيرات الكلية (Q)

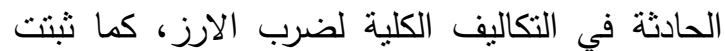
معنوية الدالة ومعلماتها إحصائياً عند مستوى معنوية الثرالية

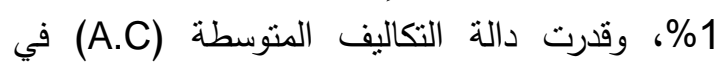
المدى الطويل من خلال قسمة دالة التكاليف الكلية (T.C) على المعادلة (2):

\section{$A . C=60.4 / Q+173.2$}

كما قدرث دالة التكاليف الحدية (M.C) في المدى الفي الطويل من خلال إجراء التفاضل الأول لدالة التكاليف

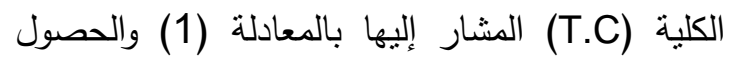

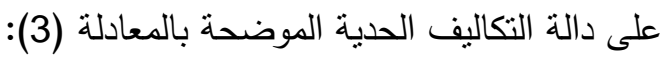

$$
M . C=173.2
$$




$$
\text { الجوهرى - العراقى - قتديل - بيومي }
$$

ثريا صادق فريد، 2010. دراسة افتصادية للوضع

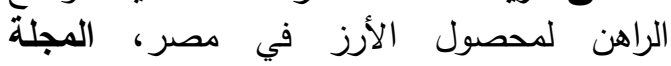
المصرية للاقتصاد الزراعي المجلد 20(1)، 40- 40

.41 سعد زكى نصار، 1994. أثر سياسة الإصلاح

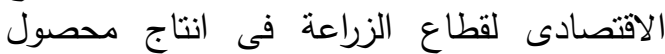

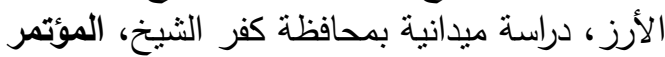
الرابع للاقتصاد والتتمية فى مصر والبلاد العرادة العربية، قسم الاقتصاد الزراعى، جامعة المنصية في النصورة، 2728 أبريل، 16 ص. ص. الرئ

صلاح محمود عبد المحسن، على عبد المحسن على الثى

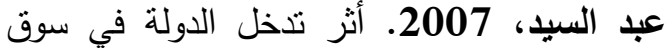

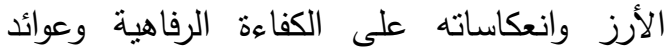

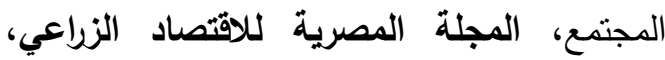

$$
\text { المجلا 17(4)، 21-22. }
$$

محمود صادق العضيمى، 1994)، فاقد ما فال بعد الحصاد فى محصول القمح والارز فى المئي، المزارع

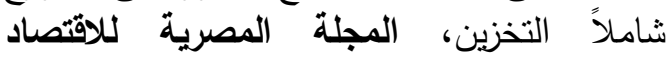
الزراعى، المجلد 2(2)، 51-52.

ثانياً: المراجع الأجنبية

Key, R. 1981. Farm Management Palming Contraband Implementation, Micgrom Hill International Book Company New Delhi, India, pp. 31-32.
عالية الجوده تعطي نسبة تصافي عالية تصل 70-

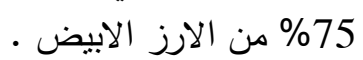

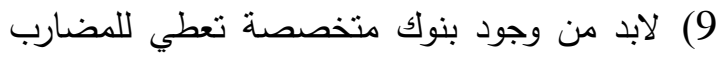

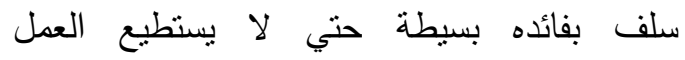
والاستمرار في السوق. 10) فتح باب التصدير بطريقة تعطي للمضارب المباب الربح المناسب والمزارع السعر الذي يغطي نكاليفه

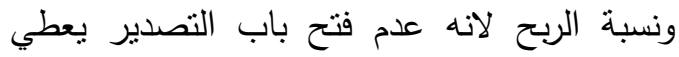

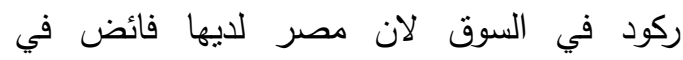
محصول الارز علاوة علي ذللك فهو أرز عالي فالي فائي

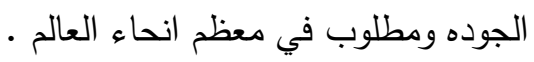

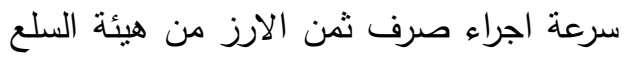
التموينية لاصحاب المضارب حتي لا تحدث لهم لهاء

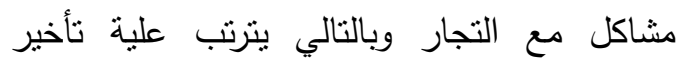
المزارع في أخذ قيمة الارز الثعير علماً بأن الهيئة

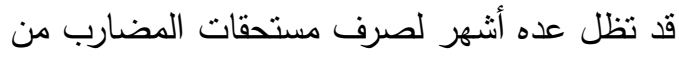

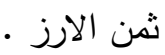

$$
\text { المراجـــ }
$$

أولاً: المراجع العربية

أحمد محمود عبد العزيز محمد، 2016. دراسة

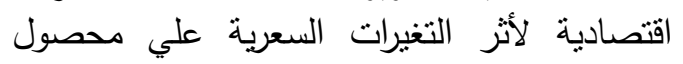

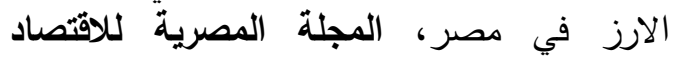
الزراعي، المجلد 26(2)، 36-37. 


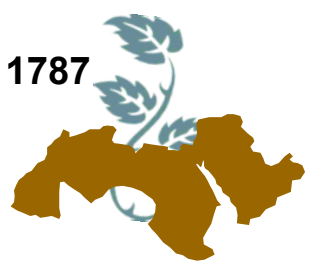

Arab Univ.

J. Agric. Sci.,

Ain Shams Univ., Cairo

Special Issue, 26(2C), 1771 - 1787, 2018

\title{
THE COSTS OF THE RICE MILLING INDUSTRY IN EGYPT
}

\author{
El-Gohry ${ }^{1}$ R.H., El-Eraky ${ }^{2}$ M.B., Kandil ${ }^{2}$ M.S. and Bayoumi ${ }^{1}$ B.A.
}

1- Samples Dept., Agricultural Economic Inst., Agric. Res. Center, Giza, Egypt

2- Agric. Economic Dept., Fac. of Agric., Ain Shams Univ., P.O. Box 68 Hadayek Shoubra 11241, Cairo, Egypt

Keywords: Cost functions, Rice multiplication, Storage costs, Rice bleaching

\section{ABSTRACT}

This research aims to study the costs of rice multiplication in order to identify the various factors that led to the high costs of beating rice in recent years. The research relied mainly on primary data from the sample of the study collected through field visits and interviews to obtain the sample data Was selected, and a random sample was selected at the level of the provinces and then at the level of centers and then at the level of villages and the number of speculators in the sample of 25 peddles distributed in the following areas three rackets in the center of Klin, Sheikh and eight rackets power center in Kafr El-Sheikh.

The problem is that there is an increase in the costs of the process of beating rice, which indicates the importance of studying the components of these costs in terms of different items and factors affecting them and the most important problems facing the industry and how to overcome them and thus Access to weaknesses and inefficiencies to raise the efficiency of this industry and propose the most appropriate solutions to improve the efficiency of this industry to achieve the lowest costs.

(Received 26 March, 2018)

(Revised 16 May, 2018)

(Accepted 10 June, 2018) 



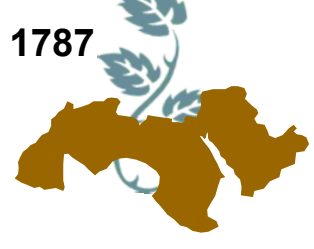

Arab Univ.

J. Agric. Sci.,

Ain Shams Univ., Cairo

Special Issue, 26(2C), 1771 - 1787, 2018

(Received 26 March, 2018)

(Revised 16 May, 2018)

(Accepted 10 June, 2018)

تحكيم: ا.د سلوى محمد عبد المنعم

ا.د محمد عبد الحافظ عبد المطلب 